\title{
Narrativas acerca do leprosário na Ilha do Pacuio em Porto Seguro: estruturas de poder sobre o Mal de Hansen, degredo e abandono sócio-político-sanitário
}

\author{
Elissandro dos Santos Santana \\ Professor da Faculdade Nossa Senhora de Lourdes \\ Colunista Socioambiental, latino-americanicista e tradutor do Portal Desacato \\ Revisor da Revista Latinoamérica \\ Membro do Conselho Editorial da Revista Letrando \\ $\triangle$ lissandrosantana@hotmail.com \\ Huillte Barbosa Jardim dos Santos \\ Graduando do Bacharelado Interdisciplinar em Humanidades - UFSB \\ ه hbjvix@gmail.com \\ Moreno Fernandes do Nascimento \\ Graduando do Bacharelado Interdisciplinar em Humanidades - UFSB \\ $\triangle$ fernandesmoreno53@gmail.com \\ Nicholas Lula Dias Ralile \\ Graduando do Bacharelado Interdisciplinar em Humanidades - UFSB \\ $\bowtie$ diasnicholas3@gmail.com \\ Radharani Cabrera Teixeira de Arruda \\ Graduanda do Bacharelado Interdisciplinar em Humanidades - UFSB \\ $\triangle$ radha.ufsb@gmail.com
}

Recebido em 18 de junho de 2017

Aceito em 13 de julho de 2017

\section{Resumo:}

Este trabalho resultou de pesquisa de campo em torno das Narrativas acerca do leprosário na Ilha do Pacuio ou dos Aquários em Porto Seguro: o degredo como vigilância e punição sanitário-social. Durante a investigação in loco, foram feitas entrevistas e aplicados questionários para compreender o objeto de estudo. Para a investigação, foram utilizados instrumentos de coleta via áudio, recorreuse à memória dos entrevistados como dispositivo de compreensão e de análise das transformações diatópico-culturais que o espaço investigado sofreu ao longo do tempo. A partir das entrevistas com os habitantes da região, de consultas a arquivos públicos e a documentos históricos, buscou-se analisar os processos de ressignificação territorial e de subjetividades sobre a Ilha por meio das narrativas memoriais dos idosos no tangente à existência, transformações utilitárias e identitárias ocorridas na Ilha ao longo das últimas décadas. Para a análise dos dados coletados, optou-se por apoiar-se nos princípios dos estudos da memória com a mediação dos aportes conceituais da Antropologia, da Filosofia e da Sociologia, com base em teóricos como Michael Foucault, Michael Pollak e Maurice Halbwachs, dentre outros. De forma objetiva, os resultados alcançados trazem à tona os capítulos silenciados da história da Ilha do Pacuio, a partir de uma análise que apresenta como o referido lócus serviu de leprosário, para o degredo, a vigilância e a punição sanitário-social até transformar-se na ilha dos Aquários, espaço de diversão, turismo e lazer na atualidade.

Palavras-chave: Leprosário; Ilha do Pacuio ou dos Aquários; Porto Seguro; Degredo; Punição Sanitário-Social. 


\title{
Narratives about the leprosarium on Pacuio Island or Aquariums in Porto Seguro: deforestation as sanitary-social vigilance and punishmen
}

\begin{abstract}
:
This work resulted from field research around the Narratives about the leprosarium in Pacuio Island or the Aquariums: the exile as surveillance and sanitary-social punishment. During the on-site investigation, interviews were conducted and questionnaires were applied to understand the object of study. For the investigation, instruments of collect by audio were used, the interviewed memory was used as a device for understanding and analyzing the diatopic-cultural transformations of the space investigated suffered over time. As of the interviews with the inhabitants of the region, public file queries and historical documents, it was sought to analyze the processes of territorial resignification and subjectivities about the Island through the memory narratives of the elderly in the tangent to the existence, utilitarian and identity transformations which have occurred on the island over the last decades. For the analysis of the collected data, it was decided to rely on the principles of memory studies with the mediation of the conceptual contributions of Anthropology, Philosophy and Sociology, based on such theorists as Michael Foucault, Michael Pollak and Maurice Halbwachs, among others. In an objective way, the results achieved bring to light the silenced chapters of the history of Pacuio Island, based on an analysis that shows how the loci served as a leprosarium for deportation, surveillance and sanitary-social punishment, Is located in the island of the Aquariums, space of fun, tourism and leisure in the present time.
\end{abstract}

Keywords: Leprosarium; Pacuio Island or Aquariums; Porto Seguro; Degredo; Sanitary-Social Punishment.

\section{Narrativas sobre la leprosería en la Isla del Pacuio o de los Acuarios en Porto Seguro: el exilio como vigilancia y castigo socio-sanitario}

\section{Resumen:}

Este trabajo es el resultado de una investigación de campo en torno a las Narrativas sobre la leprosería en la Isla del Pacuio o de los Acuarios: el exilio como vigilancia sanitario-social. Durante la investigación in situ, se aplicaron cuestionarios y entrevistas para comprender el objeto de estudio. Para la pesquisa, hubo la utilización de aparatos de recolección de datos por audio, se recorrió a la memoria de los encuestados para comprender y hacer un análisis de los cambios espaciales y culturales que el espacio investigado sufrió a lo largo del tiempo. Por medio de las encuestas con las personas de la región, consultas a archivos públicos y a documentos históricos, se buscó analizar los procesos de re significación territorial y de subjetividades con respecto a la Isla a partir de las narrativas memoriales de los ancianos en lo que se refiere a la existencia, transformaciones utilitarias y de identidad ocurridas en la Isla en las últimas décadas. Para el análisis de los datos colectados, se optó por apoyarse en los principios de los estudios de la memoria y del comportamiento humano, con la mediación de los instrumentales conceptuales de la Antropología, de la Filosofía y de la Sociología, con base en teóricos como Michael Foucault, Michael Pollak y Maurice Halbwachs, entre otros. De forma objetiva, los resultados alcanzados sacan a luz los capítulos silenciados de la historia de la Isla del Pacuio, a partir de un análisis que presenta como el referido espacio sirvió de leprosería, para el exilio, la vigilancia y punición sanitaria social hasta transformarse en la Isla de los Acuarios, espacio de diversión, turismo y ocio en la actualidad

Palabras clave: Leprosería; Isla del Pacuio o de los Acuarios; Porto Seguro; Exilio; Punición Sanitario-social. 


\section{APRESENTAÇÃO DO OBJETO DE ESTUDO}

O conceito de território é discutido por uma gama de teóricos e pesquisadores de diversas áreas do conhecimento como a História, a Geografia, a Sociologia, a Antropologia, dentre outras, e os campos conceituais que estas áreas aportam são imprescindíveis para a análise ensaística em torno do objeto de estudo no que concerne às Narrativas acerca do leprosário na Ilha do Pacuio ou dos Aquários a partir das estruturas de poder sobre a Hanseníase ou Mal de Hansen, o degredo e o abandono sanitário-sócio-político.

Diante de um arcabouço conceitual abrangente, para iniciar a discussão, foi necessário recorrer a autores pontuais como Raffestin (2010) que propõe, por exemplo, como as concepções de um território podem ser mudadas por meio das práticas ocorridas em um mesmo lugar ao longo do tempo, podendo ser alterada ou até apagadas. Partindo-se desse pressuposto, durante os meses de julho e agosto de 2016, fez-se uma pesquisa de campo sobre as narrativas, memórias provocadas e empirias histórico-discursivas de antigos moradores de Porto Seguro acerca da Ilha. Para a consecução das visitas in loco, a equipe de pesquisadores, valendo-se de instrumentos de coleta via áudio, recorreu à memória da população local como dispositivo de compreensão e de análise das transformações diatópico-culturais que o espaço investigado sofreu no decorrer da história.

Ao optar-se pelo registro oral com vistas ao resgate da memória, levou-se em consideração que para o acesso às empirias, às vivências e aos sentidos da amostra populacional entrevistada, foi importante dialogar com o cotidiano do grupo investigado, com seus ajustamentos, táticas e conformismos situados no tempo-espaço, pois os fatos, por meio do discurso, se materializam nas memórias sobre o vivido/sentido/experienciado.

Para a compreensão dos dados/análises discursivo-memoriais sobre o leprosário como lócus de degredo e punição sanitário-político-social, foi necessário observar o contexto sócio-geográfico-histórico-político-econômico-sanitário-cultural no qual os atores entrevistados, antigos moradores porto-segurenses, se inseriam. Nesse bojo, também é importante descortinar os aportes semântico-semióticos sobre as mudanças ocorridas na paisagem-topos da ilha a partir da influência dos atores internos e externos à comunidade, bem como identificar como se deram as mudanças físicas e utilitárias do local até a pósmodernidade, e dialogar com o papel que a memória coletiva e individual exerceu/exerce para o resgate histórico-cultural. Ademais, foram elaboradas indagações que despontaram 
como norte para a construção de toda a análise do resultado dos dados levantados em campo. Dentre os questionamentos, estão: quão prejudicial seria um panorama histórico na utilização da ilha no passado aos interesses de quem a comanda hoje? As mudanças no espaço físico apagam os fatos que ali ocorreram? Para assegurar os atuais modelos e, principalmente, a importância financeira que o local atual representa como empreendimento turístico, em casos como esse, a memória (e toda a cultura que um dia existiu no território) é remodelada, ignorada, esquecida e/ou até mesmo guardada para que um dia possa ser redescoberta?

A escolha do tema pesquisado se deu em torno da importância dos estudos da memória, portanto, o texto em questão objetiva servir como leitura-reflexão crítica acerca das memórias e das ressignificações locais, de forma que possa ser possível registrá-las com a devida importância que elas possuem, alocando espaço no hall da história de Porto Seguro, que teve uma mudança estrutural na forma de pensar seus paradigmas sociais. Dessa forma, este trabalho destina-se àqueles que, de alguma forma, compartilham a manifestação de desconforto ao saber que, a ilha estudada, que atualmente funciona como complexo de lazer, já foi um complexo de reclusão que abrigava, acima de tudo, seres humanos acometidos por doenças, segregados, abandonados e conceituados da pior forma possível através da força da ignorância humana e das características político-econômicas do tempo no local.

Com o objetivo exploratório e descritivo, buscou-se nesta pesquisa desvendar e compreender o objeto de estudo através de uma abordagem direta, a partir de uma pesquisa de campo com a aplicação de entrevistas a antigos moradores da região sobre o fenômeno estudado.

As entrevistas realizadas, sem exceção, foram executadas de maneira bastante informal, em uma perspectiva dialógico-discursivo-polifônica, dando pleno espaço e liberdade para o entrevistado relatar tudo o que sentia e conhecia a respeito da ilha. Todo o processo de entrevista ocorreu sem questionários programados, construídos no contato discursivo, à medida que os diálogos aconteciam entre os pesquisadores e os atores sociais entrevistados, dependendo da resposta apresentada e de questões importantes que iam se desvelando no discurso. Porém, a informalidade das entrevistas não deixou espaços para a falta de rigor científico, pois todos os integrantes foram a campo com metas e perguntas preestabelecidas para que o objetivo da pesquisa não fosse desvirtuado nem ficasse confuso. 
Os pesquisadores, no ato das entrevistas, estavam atentos aos sentimentos, gestos e aos sinais expressos pelos entrevistados, passo importante para a compreensão da memória pessoal que é tão trabalhada na pesquisa. Além das entrevistas realizadas, houve também uma consulta a arquivos bibliográficos, tais como Museus e Cartório de Registros da cidade de Porto Seguro, com o objetivo de encontrar dados e informações que fundamentassem os resultados da pesquisa.

\section{CONSIDERAÇÕES TEÓRICAS SOBRE O TURISMO E O PACUIO}

A matriz de produção, geração de emprego e de renda em Porto Seguro é o Turismo e pensar esta atividade requer visualizá-la como produto. Coriolano (2006) apresenta que este produto é abstrato, pois trata da venda da imagem de um local destituído de conteúdo social em detrimento da construção de um espaço-fantasia dos cartões-postais. Partindo-se do pressuposto apresentado pelo teórico anterior, é possível elaborar uma ponte conceitual com o que afirma Santana (2016) quando este pontua que os atores sociais envolvidos com o turismo na cidade de Porto Seguro desenvolveram práticas exploratórias do capital natural e essa concepção também aparece no discurso do turista que concebe a região como pacoteobjeto a ser consumido.

Diante do exposto acima, é oportuno recorrer à discussão que Cara (1996) faz quando pontua que o turismo ao se materializar em determinado espaço, pode tanto artificializa-lo como artificializar e criar imagens ilusórias e descaracterizar a identidade cultural da população hospedeira, criando desta forma, uma cadeia de processos que os geógrafos denominam "turistificação". Já a partir de Santos (2002) observa-se que para que estes mesmos espaços turísticos permaneçam atrativos é preciso, constantemente, realçar suas virtudes ${ }^{1}$.

Considerando-se as minúcias que caracterizam a Ilha do Pacuioº ${ }^{2}$, sua desconstrução e reconstrução enquanto signo da cidade até ser reconhecida como Ilha dos Aquários, uma

\footnotetext{
$1 \quad$ Na ilha, os símbolos foram forjados para o turismo, mas não herdados de sua história real.

2 Segundo o historiador Romeu Fontana, a ilha recebeu esse nome em função dos peixes presentes naquele ecossistema por nome Pacus.
} 
análise que se sustente na concepção antropológica do turismo nas sociedades modernas é fundamental para compreender o traçado que visa a comunicar este conceito à definição que Raffestin (2010) usa para território. Tal exercício crítico só é possível mediante o empréstimo da linha de raciocínio usada por Michael Pollack, pois o referido autor credita ao efeito de reivindicação social o resgate intacto das memórias inaudíveis que ele chama de 'clandestinas'. A problemática, e por que não antítese, reside no conflito que o resgate dessas memórias causa ao efeito turistificação. Ora, tendo ratificado o espaço turistificado como imagem na publicidade dos espaços da cidade, não é coerente atribuir à imagem do produto qualidade que causa repulsa e, consequentemente, rejeição (KOTLER, 2000). Convencionar a imagem já internacionalmente vendida de entretenimento e diversão com a ciência de que ali pode ter funcionado um sistema de reclusão e opressão social, pode dar resultados que tem potencial para resgatar memórias que a própria cidade marginalizou, justificando as cíclicas mudanças que Bloch (2002) reitera ao reconhecer que esse tempo verdadeiro é, por natureza, um continuum e também perpétua mudança.

Le Goff (1992) apresenta um conceito sobre memória coletiva que coaduna com o que foi mencionado no parágrafo anterior, (...) Do mesmo modo, a memória coletiva foi posta em jogo de forma importante na luta das forças sociais pelo poder. Tornar-se senhor da memória e do esquecimento é uma das grandes preocupações das classes, dos grupos, dos indivíduos, que dominaram e dominam as sociedades históricas. Os esquecimentos e os silêncios da história são reveladores destes mecanismos de manipulação da memória coletiva.

Partindo-se do desafio de colher informações que corroborem os relatos locais, este recorte configura-se como cenário útil para o emprego da linha pollakiana dos estudos da memória. Justifica esta escolha a competência do autor e sua vivacidade ao definir e estudar as memórias individuais e coletivas tratando-as como eventos pelos quais é possível dialogar com o tema de pesquisa adotado. Porém, tendo reconhecido as diversas nuances que o tema proposto carrega e comporta, registra-se a ambição de elencar outros autores que também tratam dos estudos da memória e da identidade no âmbito da Antropologia.

O problema que se coloca em longo prazo, para as memórias clandestinas inaudíveis, é o de sua transmissão intacta até o dia em que elas possam aproveitar uma ocasião para invadir o espaço 
público e passar do não dito à contestação e à reivindicação; o problema de toda memória oficial é o de sua credibilidade, de sua aceitação e também de sua organização. (POLLACK, 1989)

\section{A VILA APÓS A SEGUNDA GUERRA MUNDIAL E AS INFLUÊNCIAS DO POLICIAMENTO MÉDICO SANITARISTA}

Após a Segunda Guerra Mundial, Porto Seguro inserida em uma região que ainda não havia se descoberto para o turismo, a existência deste lugar na rota dos principais destinos turísticos do mundo era algo que nem o mais gabiru ${ }^{3}$ dos nativos imaginava. A atual cidade de Porto Seguro, na época, vila, encravada no Sul da Bahia, sem existência no mapa político ${ }^{4}$ era cortada por rios, cercada pela Mata Atlântica, no litoral e distante do fluxo populacional.

A “Terra do Descobrimento" carregava os traços de um local ainda não descoberto, era de difícil acesso e quase nenhuma estrada possuía pavimentação. Cerca de duas mil pessoas compartilhavam o que há tempos vinha sendo o retrato fiel de um Brasil ainda reconhecidamente rural, de extrema pobreza, saúde precária e quase nada em educação ${ }^{5}$.

Porto Seguro era o lar de poucos habitantes e o efeito direto foi observado pela alta taxa de endogamia ${ }^{6}$. Pelas dificuldades de acesso, a saúde era um dos serviços mais escassos. Hospitais e postos de saúde surgiram apenas algumas décadas mais tarde. Não havia médicos no território e somente em 1953, segundo um dos entrevistados, chegou ao município um profissional, que, por muito tempo, foi o responsável pela saúde de toda a região.

Em uma vila sem acesso à educação, com defasada distribuição de renda e sem estrutura médica, as pessoas que contraiam doenças para as quais não era possível dar um diagnóstico clínico, e que ofereciam potenciais riscos à saúde coletiva, eram retiradas do convívio social. Uma dessas doenças, a mais estigmatizada das enfermidades, a lepra, termo

\footnotetext{
$3 \quad$ Assim eram chamados os nativos de Porto Seguro.

4 Adaptação da transcrição de áudio do historiador Romeu Fontana.

5 Adaptação da transcrição de áudio de morador idoso.

6 Endogamia é um sistema em que os acasalamentos se dão entre indivíduos aparentados, relacionados pela ascendência.
} 
em desuso, pela carga de preconceito que carrega, atualmente, conhecida como Hanseníase ou Mal de Hansen. Cunha (2005) considera que o entendimento sobre este termo consistia em símbolo da impureza moral. Justa (apud Souza-Araújo, 1956 apud Feitosa et al 2014) avança ao afirmar que a lepra significava:

[...] mais do que uma doença; vale uma condenação; fere o ser humano desde os tempos bíblicos, marcando o dedo com o ferro do pavor por parte dos outros; faz dele um réprobo, um banido; uma doença-terror que horripila e segrega, porque desconhecida a natureza do agente provocador. E então, o remédio é isolar o doente do convívio social.

Em uma ação que possibilita questionar a imagem que os brasileiros reproduziram a partir da identidade oriunda da Polícia Médica $^{7}$ e fundada pela definição freudiana do homem conflitivo e, sobretudo, impulsivo, afirma-se que a tentativa de erradicar os prováveis surtos das doenças que dificilmente poderiam ser combatidas foi socialmente convalidada mediante espécime de simulacro de apartheid ${ }^{8}$, uma clara reclusão social que configurou arquétipo de aplicação do controle sanitário inerente à época. Dessa forma, analisa-se que a "segregação obrigatória desses doentes, que, no início, parecia autoritária, detinha a intenção de preservação da saúde coletiva.” (CASTRO, 2003).

Geralmente, locais de reclusão como o Pacuio eram escolhidos pela distância da área urbana com o intuito de manter os enfermos totalmente isolados. É importante destacar que o isolamento insular como meio de reclusão de pessoas com doenças incuráveis para a época, como a hanseníase, se deram em várias partes do Planeta. Para a compreensão desse quadro histórico, é oportuna a leitura de artigos e outros trabalhos como o de Zamparoni (2017), Lepra: doença, isolamento e segregação no contexto colonial em Moçambique e o de Ramos (2017), Hanseníase e estigma no século XXI: narrativas de moradores de um território endêmico. No trabalho de Zamparoni, por exemplo, há registros de ilhas utilizadas para o isolamento de pessoas com hanseníase, naquele contexto, nomeada como lepra, no Continente Africano.

$7 \quad$ Oficializada em 1808 pela Família Real, o termo vem do original Medizinichepolizei e significa "polícia médica”. Foi utilizado pela primeira vez na Alemanha, em 1764, por Wolfong Thomas Rau, em seu livro "Reflexões sobre a utilidade e a necessidade de um regulamento de polícia médica para um Estado".

$8 \quad$ Significa "vidas separadas" na Língua Africâner. 
Acerca desses espaços, com vistas à análise de que as práticas de isolamento insular se repetiram em várias partes do Planeta e não somente no Pacuio, é profícuo recorrer ao que afirma Zamparoni (2017) ao discutir a hanseníase como doença, isolamento e segregação no contexto colonial em Moçambique:

Essas são evidências da aplicação em terras coloniais, em extremo, do termo "isolar": "isola", "ilha". Desconectados do mundo, na ilha, os internos eram quase abandonados à própria sorte; faltava alimentação, e o fornecimento de medicamentos era parco e incerto. Em Massavelene, os doentes que não estavam incapacitados eram obrigados aos trabalhos agrícolas, mas, por diversas razões, entre elas as climáticas, as colheitas eram insuficientes, e a escassa e pobre alimentação que o Estado provia não chegava no momento devido nem era suficiente para atender às necessidades.

Em Porto Seguro, o espaço escolhido foi a Ilha do Pacuio, principalmente, por ser separada da cidade pelo Rio Buranhém que se dividia em dois braços de rios ${ }^{9}$ conhecidos como Curitiba e Santo Antônio, e tinha como única forma de acesso canoas que tornavam o isolamento eficaz.

Porto Seguro, naquele contexto histórico, não possuía médicos, ou seja, o isolamento dessas pessoas não lhes garantia um tratamento, pelo contrário, a reclusão poderia até agravar ou desencadear outras doenças. $\mathrm{Na}$ época, se acreditava que a lepra era transmitida pelo ar, os moradores tinham receio do contato com essas pessoas, mesmo sem o devido diagnóstico da doença, houve inclusive um caso em que a população quis enviar à ilha uma criança ${ }^{10}$ de cinco anos de idade, com catapora, por achar que estava com lepra.

Entende-se que a ilha foi adotada como estrutura de isolamento do tipo leprosário, com o objetivo de manter o controle de doenças transmissíveis. Ressalta-se o fato de que as pessoas reclusas na ilha não recebiam nenhum suporte digno de moradia, já que os próprios

\footnotetext{
Informação obtida na transcrição de áudio de morador idoso.

10 Adaptação da transcrição de áudio de morador idoso.
} 
degredados tinham que construir suas moradias, na época, feitas de sopapo ${ }^{11}$ e cobertas com palha.

A construção coletiva de moradias pelos degredados imprime um sentido de coletividade e, acerca disso, é possível compreender o conceito de comunidade apresentado por Bauman e May (2010). A partir destes autores, verifica-se que, para que seja possível usar o termo comunidade, um grupo de pessoas deve comungar algum tipo de concordância em algum tema ${ }^{12}$.

$\mathrm{Na}$ ilha, por compartilharem similaridades tão intimamente sentidas enquanto sujeitos, rompe-se com qualquer hipótese cujo alvo seja a desconstrução da ideia de que ali, para além da definição atual de leprosário ou ilha de quarentena, de fato funcionou uma organização com funções distribuídas, com membros não arguidos da condição em que se encontravam, porém, minimamente coordenados no sentido de se manterem vivos. De tal forma que, mesmo abandonados pela sociedade oficial da cidade, com pouco ou quase nenhum suporte, ao ponto de os próprios membros terem de construir suas moradias, não há dúvidas de que a Ilha do Pacuio foi uma comunidade de leprosos mediante a sustentação e interconexão entre seus membros. Nessa linha, Bauman e May (2010) fundamentam que: “os fatores unificadores são valorizados como mais fortes e importantes do que qualquer coisa que possa causar divisões, e as diferenças entre os integrantes". Nessa linha, é importante compreender que a maneira como um grupo, para manter-se e se proteger, pratica exclusões, estabelece as formas de assistência, reage ao medo da morte, recalca ou alivia a miséria, intervém nas doenças ou as abandona em seu curso natural (FOUCAULT, 1994, p. 16).

\section{DIÁLOGOS DE MEMÓRIAS E ANÁLISE DAS ENTREVISTAS}

Antes de qualquer resultado por meio dos áudios dos entrevistados, é importante destacar que para a consecução da análise do material discursivo dos entrevistados foram

\footnotetext{
$11 \quad$ Termo utilizado pelo entrevistado, importante historiador da cidade de Porto Seguro, a partir das transcrições dos diálogos da entrevista (2017), significa casa feita de varas cobertas de barro na parede, mais conhecida também como pau-a-pique.

12 Na redação oficial, além do já citado, é também concordar “[...] com algo que outras rejeitem e que, com base nessa crença, atestar alguma autoridade." (Adaptação) (BAUMAN e MAY, 2010, p. 75)
} 
feitas intercalações entre os dados analisados a partir das entrevistas, dos aportes teóricos e das citações que fundamentem/ sustentam essa comunicação científica.

Os fatos silenciados-apagados no que se refere à história da Ilha do Pacuio são, no mínimo, instigantes, por isso, ao analisar em profundidade o papel da memória para o tecido social porto-segurense, as funções em grupo ou em âmbito individual, as circunstâncias que despertam a utilização e os pontos da história em que ela se aplica, na maioria das vezes, não se compreende, com precisão, como se dão as transformações temporais, mesmo que se faça parte delas; os acontecimentos corriqueiros que constroem passo a passo a história não despertam o interesse social e isso implica em deduzir que a memória está diretamente atrelada ao passado, às lembranças, aos sentimentos e às emoções que um grupo ou um indivíduo viveu.

A única forma de se reviver acontecimentos do passado é através da memória, pois ela serve como um elo atemporal que é capaz de trazer o passado para o presente de forma efetiva, com o poder de, mesmo após vários anos, despertar emoções diversas nas pessoas. Nesse sentido, Ricoeur (1994, p. 41), valendo-se de um conceito sobre o tempo apresentado por Santo Agostinho, elucida a seguinte questão:

0 achado inestimável de santo Agostinho, reduzindo a extensão do tempo à extensão da alma, é o de ter ligado essa distensão à falha que não cessa de se insinuar no coração do tríplice presente: entre o presente do futuro, o presente do passado e o presente do presente. Assim, ele vê a discordância nascer e renascer da própria concordância entre os desígnios da espera, atenção e memória.

Ao analisar, de forma objetiva, o que afirma o teórico acima, que tem como base os escritos de Santo Agostinho, fica nítido a função que a memória desempenha na história e isso ficou bastante evidente na recuperação da memória sobre a atual Ilha dos Aquários a partir dos discursos memoriais das pessoas entrevistadas. Do total de cinco entrevistados, em todas as situações de diálogo, ao longo da aplicação dos questionários de entrevista, os dados, as imagens e os fatos foram apresentados e essas informações que até hoje não são conhecidas por grande parte da sociedade porto-segurense contribuirão para a escrita de parte de outro capítulo da história da cidade. 
No processo de construção dessa pesquisa, foi possível vivenciar esse tipo de experiência afetiva memorial que aporta novos sentidos e fatos históricos ao município de Porto Seguro. Em um determinado momento da entrevista, em uma das falas de uma das pessoas entrevistadas, constataram-se duas situações distintas: a princípio, ela afirmou que não possuía lembranças sobre o assunto e, em outra situação à frente, demonstrou uma reação totalmente oposta quando não conteve a emoção ao cantar um fado, canção que se caracteriza pelos tons sentimentalistas e melancólicos. Naquele momento, presenciou-se a aplicação da memória ligando passado e presente.

Essa junção entre passado e presente se deu em diversas situações nas entrevistas realizadas. Por exemplo, na gravação realizada no dia 12 de agosto de 2016, um dos entrevistados ao ser questionado sobre qual o nome da Ilha dos Aquários antes do lugar receber o referido nome, respondeu o seguinte: (...) ali foi uma colônia de leproso... Um historiador bastante conhecido em Porto Seguro sempre fala que a Ilha dos Aquários se chamava Ilha do Pacuio.

Em situações como as narradas acima, é possível observar como a memória pode exercer funções variadas dentro de um determinado grupo, e, dependendo da importância histórica dos fatos, haverá diferentes formas de utilização da memória. Muitas vezes, ela pode servir como objeto modelador de um passado que se deseja esquecer, já em outras, ela servirá como base para reacender lembranças positivas. Sendo assim, compreende-se que a pluralidade das funções memoriais de um grupo relaciona-se de forma distinta com as questões coletivas e individuais. Nessa perspectiva, é necessário recorrer ao que apresenta Nora (1993, p. 14): "porque é afetiva e mágica, a memória não se acomoda a detalhes que a confortam; ela se alimenta de lembranças vagas, telescópicas, globais ou flutuantes, particulares ou simbólicas, sensivel a todas as transferências, as cenas, a censura ou projeções".

Sabe-se das diferenças que exercem a positividade e a negatividade dos sentimentos sobre os seres humanos. Relatar momentos de glória e êxito em louvor próprio, quase sempre é feito com riqueza de detalhes e orgulho, enaltecendo acontecimentos e o reconhecimento do outro sobre si, para que, dessa forma, sejam expostas as virtudes e as realizações como ser humano. Na contrapartida das boas emoções, as vivências negativas carregadas de sofrimento e de dor exercem influência contrária nos autos relatos. Quando o ser humano é questionado sobre assuntos que possuem alguma carga afetiva negativa ou traumática, esquivando-se, adiando, omitindo ou falando muito pouco sobre aquilo, 
permitindo, assim, um possível resguardo das dignidades da visão coletiva. Acerca disso, é oportuno recorrer ao que pontua Pollack (1989):

E algumas vítimas, que compartilham essa mesma lembrança "comprometedora", preferem, elas também, guardar silêncio. Em lugar de se arriscar a um mal-entendido sobre uma questão tão grave, ou até mesmo de reforçar a consciência tranquila e a propensão ao esquecimento dos antigos [...], não seria melhor se abster de falar?

A citação acima coaduna com um dos mais interessantes e emocionantes relatos concedidos ao resgate memorial da Ilha do Pacuio, a partir das lembranças de um dos entrevistados quando, ao ser indagado sobre seu possível envio para o território da reclusão, se manifestou da seguinte maneira: "Eu não tenho lembrança não, eu tive foi catapora braba. Depois minha vó contou que uma amiga e outras pessoas se afastaram de casa, com medo que fosse lepra, que eu não tive lepra, foi catapora braba".

Observa-se acima uma resposta direta que, automaticamente, intimidaria o grupo de pesquisadores a fazer perguntas mais incisivas que pudessem aflorar recordações desagradáveis. "Não tenho lembrança não, eu tive foi catapora braba" Em seguida, observou-se uma exteriorização mais tranquila sobre a experiência do entrevistado com a catapora, doença que, atualmente, é livre de preconceitos, o que não ocorre com a hanseníase, enfermidade historicamente estigmatizada desde as passagens bíblicas, "mal de Lázaro", até as infelizes referências aos cães leprosos que vagam pelas ruas. A sociedade da época, temerosa pelo contato direto com pessoas acometidas pela doença, logo se afastava de seu entorno, de sua própria casa e, a partir disso, é possível ter uma dimensão da consequência que um possível reconhecimento de "leproso" poderia desabar sobre uma pessoa, ou até mesmo sobre uma família na época.

O relato do entrevistado apresentado acima confirma o que pontua Nora (1981, p. 14): “Tudo que hoje é chamado de memória, não é, portanto, memória, mas já história. Tudo o que é chamado de clarão de memória é a finalização de seu desaparecimento no fogo da história. A necessidade da memória é uma necessidade da história".

A inexistência de lugares de memória, de uma história material e imaterial a respeito da cronologia territorial da ilha, como museus e memoriais, a exemplo dos hospitais 
psiquiátricos que, na segunda metade do século passado, também serviram como locais de reclusão para os mais variados tipos de grupos socialmente indesejados, ainda que, em maior escala, é uma causa provável para que as vivências ocorridas no Pacuio não sejam narradas de modo a realimentar as memórias familiares das vítimas com um espírito reflexivo dos sofrimentos ali imputados.

Tais monumentos à memória coletiva possibilitaram a devolução da dignidade a todos aqueles que foram atingidos por processos de injustiças e exclusões de toda ordem durante a história da humanidade. Nesse âmbito, Pollack (1989) menciona que as "lembranças proibidas são indiziveis e/ou vergonhosas; são, zelosamente, guardadas e passam despercebidas pela sociedade". Já Halbwachs (1990) coloca:

Enquanto uma lembrança subsiste, é inútil fixá-la por escrito, nem mesmo fixá-la, pura e simplesmente. Assim, a necessidade de escrever a história de um período, de uma sociedade, e mesmo de uma pessoa desperta somente quando eles já estão muito distantes no passado, para que se tivesse a oportunidade de encontrar, por muito tempo ainda em torno de si, muitas testemunhas que dela conservem alguma lembrança.

Como mencionado anteriormente, todos os acontecimentos de hoje formam as memórias que a sociedade terá no futuro, mas a importância do presente, muitas vezes, não é percebida. Surge, então, a necessidade de fixar a memória através de algum mecanismo.

Sabe-se que antigamente a história era toda construída de forma oral, que os fatos e os acontecimentos eram eternizados através da fala, mas, atualmente, essa preservação possui como aliada ímpar a escrita. São raros os exemplos de grupos sociais que não tenham, pelo menos, alguma pista de seu passado relatado.

O êxito do estudo de um determinado grupo está proporcionalmente ligado à quantidade de informações que se tem dele. Para que exista enriquecimento da pesquisa, é necessário que haja detalhamento informativo, porém, muitas vezes, os acontecimentos e lembranças de um grupo são propositalmente esquecidos, como é o caso da Ilha do Pacuio ou dos Aquários.

A memória ainda possui suas funções ligadas às boas lembranças, mas é necessário descosturar essa cultura, pois os acontecimentos, mesmo que sejam desagradáveis, são 
importantes para preservar a história e marcos, entendendo que o presente constrói a história e só assim a memória poderá, futuramente, cumprir suas funções.

Os resultados alcançados na pesquisa possibilitam a materialização da história oral através da escrita, pois a partir dos 5 sujeitos de pesquisa entrevistados, foi possível fazer um levantamento discursivo-memorial que contribui para trazer à tona parte de uma história silenciada no município.

Para detalhar parte das memórias sobre a Ilha do Pacuio ou dos Aquários, abaixo serão apresentadas tabelas com especificações discursivas de transcrições a partir de respostas apresentadas pelos moradores entrevistados ara alguns dos questionamentos elaborados nas entrevistas feitas em julho e agosto de 2016.

No Quadro 1, é possível compreender o que era a Ilha dos Aquários antes de receber esse nome, bem como entender se eram enviadas para a Ilha somente as pessoas com Hanseníase ou Mal de Hansen. De acordo com as falas listadas abaixo do entrevistado 1, podese perceber que, para a cultura da época, a segregação de indivíduos, quer pela doença em si, ou por outro motivo justificado para a época, era considerada normal e aceita por estes indivíduos. Na entrevista também ficou evidente que na ilha não ficavam somente pessoas com Hanseníase ou Mal de Hansen, mas, também, outras pessoas que contraíam doenças consideradas contagiosas ou incuráveis para a época. 
Quadro 1 - Memórias narradas acerca de como se chamava a Ilha dos Aquários anteriormente

\begin{tabular}{|c|c|}
\hline $\begin{array}{l}\text { QUESTIONAMENTOS } \\
\text { ELABORADOS PELOS } \\
\text { PESQUISADORES }\end{array}$ & ENTREVISTADO 1 \\
\hline $\begin{array}{l}\text { O que era a Ilha dos } \\
\text { Aquários antes de receber } \\
\text { este nome? }\end{array}$ & $\begin{array}{l}\text { Na realidade, é uma coisa engraçada, né? Não sei se você sabia, } \\
\text { mas ali foi uma colônia de leproso e meu pai... Ele foi médico aqui } \\
\text { há } 63 \text { anos. (...) lá foi uma ilha de leproso. Tem até um escritor e } \\
\text { historiador aqui em Porto Seguro muito conhecido, não sei se } \\
\text { vocês conhecem... Ele sempre fala sobre a Ilha dos Aquários. Lá } \\
\text { chamava Ilha do Pacuio. }\end{array}$ \\
\hline $\begin{array}{l}\text { O senhor sabe informar se } \\
\text { na ilha ficavam somente } \\
\text { pessoas com Hanseníase ou } \\
\text { Mal de Hansen? }\end{array}$ & $\begin{array}{l}\text { Não só os leprosos ou tinha mais alguma coisa que não se } \\
\text { encaixava no perfil da época. Não, é porque o seguinte, naquele } \\
\text { tempo a lepra não era como hoje, só que hoje } 99,99 \% \text { dos casos ela } \\
\text { só é contagiosa naquele estágio em que está bem avançado, mas } \\
\text { naquele tempo não tinha medicação e tinha também estigma } \\
\text { muito grande né, então quando a pessoa (ficava doente) a própria } \\
\text { família (mandava pra ilha), aí meu pai uma ia lá uma vez por } \\
\text { semana pra atender o pessoal e o barqueiro levava os } \\
\text { mantimentos; as outras famílias levavam, mas o Barqueiro ia } \\
\text { morrendo de medo pô diz que ele não descia da canoa de jeito } \\
\text { nenhum, o que era natural e o meu pai dizia que não tinha } \\
\text { problemas que a lepra era só contato pela saliva, mas vai você } \\
\text { dizer isso. }\end{array}$ \\
\hline $\begin{array}{l}\text { O senhor mencionou que } \\
\text { seu pai foi médico lá. Pode } \\
\text { falar um pouco sobre isso? }\end{array}$ & $\begin{array}{l}\text { Ele era o único médico que tinha nessa região toda. Ele atendia de } \\
\text { Porto Seguro até Caraíva e Guaratinga. Naquele tempo, pra ir para } \\
\text { Guaratinga ele tinha que ir de cavalo até Vera Cruz. De Vera Cruz } \\
\text { pegava o rio até Eunápolis. Em Eunápolis outro cavalo até aquele } \\
\text { rio que passa por Guaratinga e aí descia pra ir. Na Ilha do Pacuio } \\
\text { era ele que ia, o barqueiro ficava apenas ali, ele que descia. }\end{array}$ \\
\hline
\end{tabular}

Fonte: Elaborado pelos autores da pesquisa a partir de transcrição de fitas de áudio com os entrevistados (2017).

No Quadro 2, abaixo, a partir das transcrições da entrevista com o entrevistador 2, importante historiador do município de Porto Seguro, pode-se analisar se a atual Ilha dos Aquários era uma Colônia de pescadores, quem era enviado ao leprosário e o porquê do nome Ilha do Pacuio e como as pessoas eram enviadas para lá. 
Narrativas acerca do leprosário na Ilha do Pacuio em Porto Seguro: estruturas

de poder sobre o Mal de Hansen, degredo e abandono sócio-político-sanitário

A fala do entrevistado no quadro 2, corrobora a informação apresentada no quadro 1 no tangente ao fato de que não somente pessoas com Hanseníase eram enviadas para o degredo na Ilha. $\mathrm{O}$ fragmento discursivo que aparece no quadro abaixo, o entrevistado cita um caso de uma pessoa enviada para a Ilha sem hanseníase "Ele teve aquelas bexigas de "berna", coisa que dá em animal, boi. Como as pessoas não sabiam que doença se tinha se colocava lá", corrobora que a Ilha serviu como espaço de isolamento para qualquer doença que fosse vista como contagiosa ou incurável.

Quadro 2 - Diálogo com historiador local para historicizar questões sobre a atual Ilha dos Aquários

\begin{tabular}{|c|c|}
\hline $\begin{array}{l}\text { PERGUNTAS DOS } \\
\text { PESQUISADORES }\end{array}$ & ENTREVISTADO 2 (HISTORIADOR) \\
\hline $\begin{array}{l}\text { Algumas pessoas contam } \\
\text { que a atual Ilha dos } \\
\text { Aquários anteriormente era } \\
\text { uma Colônia de pescadores. } \\
\text { O senhor poderia discorrer } \\
\text { sobre essa questão? }\end{array}$ & $\begin{array}{l}\text { Foi colônia de pescadores coisa nenhuma; gente que morou sim, } \\
\text { mas não teve nada de colônia de pescadores. Eu tô falando de } \\
\text { antes, bem antes. Aí é Ilha do Pacuio que era um leprosário, sabe o } \\
\text { que é né? }\end{array}$ \\
\hline $\begin{array}{l}\text { O senhor saberia dizer } \\
\text { quem era enviado a esse } \\
\text { leprosário? }\end{array}$ & $\begin{array}{l}\text { Quando as pessoas, até a minha geração mesmo, sabe, tem um } \\
\text { rapaz aqui, que tá vivo; ele tem uns } 68,69 \text { anos, então não é tanto } \\
\text { tempo assim. Ele teve aquelas bexigas de "berna", coisa que dá em } \\
\text { animal, boi. Como as pessoas não sabiam que doença se tinha se } \\
\text { colocava lá. Quando a pessoa tinha uma doença natural, nós } \\
\text { estamos falando de uma cidade (Porto Seguro) que não é essa que } \\
\text { você conhece né, e não foi também a que eu conheci. As pessoas } \\
\text { que tinham alguma posse eram enterradas nas igrejas, mas } \\
\text { quando tinham uma doença que não se sabia, então não podia } \\
\text { enterrar porque ora, enterrava na igreja, na igreja CA-Tó-LI-CA, só } \\
\text { pra você entender que era a igreja Católica que mandava no } \\
\text { mundo. Aqui não tinha evangélico, era tudo católico. Então a } \\
\text { pessoa que tinha uma doença que não se sabia o que era, quando } \\
\text { morria era enterrada na igreja. \{...\} Morreu de quê? Não sabe. Não } \\
\text { sabe? Então, enterra no mato. Onde é o mato? O mato é aqui, por } \\
\text { isso, Rua Cova da Moça. Quando eu era menino, essa rua que nos } \\
\text { chegou aqui, pra pegar a rodovia ela foi enterrada ali, por não se } \\
\text { saber qual doença ela tinha, a mesma coisa acontecia com Pacuio, } \\
\text { quando você tinha uma doença, ela era transmissível, e não tinha } \\
\text { médico pra diagnosticar, então você mandava prum lugar deserto, } \\
\text { onde era o lugar deserto? Lá. }\end{array}$ \\
\hline
\end{tabular}


E Ilha do Pacuio, por que este nome e como as pessoas eram levadas para lá?
Por causa dos Pacus. Pacu é um peixe. Pacus. E essa ilha foi comprada no final da década 70/80 por uma pessoa do Rio de Janeiro. É importante dizer que quando você botava as pessoas lá, elas tinham que ficar lá. Você pegava uma canoinha, ia pra lá, levava mantimento, as coisas e deixava lá. Eu não peguei isso, mas tinha um amigo meu mais novos do que eu 2, 3 anos, que as pessoas queriam que ele fosse pra lá, porque ele tava com aquelas coisa berna, aquele negócio que dá em cavalo que na época não se sabia o que era. Hoje se sabe, tem médicos.

Fonte: Elaborado pelos autores da pesquisa a partir de transcrição de fitas de áudio com os entrevistados (2017).

No Quadro 3, a seguir, o entrevistado 2, como mencionado, historiador de Porto Seguro, responde se é fato o que se ouve por aí que quando as mulheres não conseguiam casar, eram enviadas para a Ilha, também, se só ia para a Ilha quem tinha Hanseníase ou Mal de Hansen e se a pessoa que era enviada e não possuía uma família economicamente privilegiada ficava à mercê da sorte.

Quadro 3 - Somente pessoas com Hanseníase ou Mal de Hansen eram enviadas para a Ilha?

\begin{tabular}{|l|l|}
\hline \multicolumn{1}{|c|}{$\begin{array}{c}\text { QUESTIONAMENTOS FEITOS PELOS } \\
\text { PESQUISADORES }\end{array}$} & \multicolumn{1}{|c|}{ ENTREVISTADO 2 (HISTORIADOR) } \\
\hline $\begin{array}{l}\text { Um dos entrevistados mencionou que quando } \\
\text { as mulheres não conseguiam casar, elas eram } \\
\text { enviadas para a Ilha. Isto é verdade? }\end{array}$ & $\begin{array}{l}\text { Não é verdade. Isto não passava de uma } \\
\text { brincadeira da época. Essa cidade é } \\
\text { endogâmica, quer dizer, por ter poucos } \\
\text { habitantes existia constantemente o } \\
\text { casamento de pessoas do mesmo sangue, } \\
\text { principalmente de primos e isso se chama } \\
\text { endogamia; então, nem toda mulher conseguia } \\
\text { casar, isso era uma desonra naquele tempo. } \\
\text { Eram denominadas como "as que ficaram para } \\
\text { titia", vale ressaltar que aqui, naqueles tempos, } \\
\text { muitas mulheres morreram virgens. Então por } \\
\text { isso, por a mulher não ter casado, diziam que } \\
\text { ela iria pra lá. Mas na verdade era tudo uma } \\
\text { brincadeira. }\end{array}$ \\
\hline
\end{tabular}


Então, só ia para a Ilha quem tinha Hanseníase ou Mal de Hansen?

A pessoa que era enviada para lá e não possuía uma família economicamente privilegiada ficava à mercê da sorte?
Não, a pessoa que tinha alguma doença que aparentava ser contagiosa e deveria se afastar da sociedade, faziam isso mandando pro Pacuio.

Olhe bem, na época, a cidade era pequena, as famílias eram basicamente de pescadores, ou seja, foram poucas as pessoas que foram mandadas para lá, não era aquela coisa de leprosário de grande porte. Utilizava-se o espaço para leprosário, mas era pouca gente, e não precisava ser lepra, qualquer doença desconhecida que apresentasse algum risco à população.

Fonte: Elaborado pelos autores da pesquisa a partir de transcrição de fitas de áudio com os entrevistados (2017).

As falas apresentadas por cada entrevistado que aparecem nos quadros 1 , 2 e 3 são cruciais para um novo capítulo sobre a história de Porto seguro no que se refere ao silenciamento sobre os fatos ocorridos na Ilha do Pacuio, atual Ilha dos Aquários.

\section{ALGUMAS CONSIDERAÇÕES FINAIS}

A Ilha do Pacuio, provavelmente, começou a ser usada como leprosário a partir do século XIX, conforme mencionou um dos entrevistados que é um dos mais importantes historiadores da cidade, estendendo-se até o início de 1950. Ao longo do tempo, passou por inúmeros processos que alteraram suas características físicas e conceituação identitária, principalmente no que concerne às memórias que lhe são atribuídas.

Pesquisar acerca de um tema tão delicado, que se dissipou historicamente, não constitui tarefa fácil, de forma que nem sempre as pessoas estão dispostas a falar sobre esse tipo de situação. Contudo, tais acontecimentos não devem ficar soterrados no tempo, dado a importância que comportam.

A partir das falas dos entrevistados nos quadros 1, 2 e 3, foi possível analisar como se deu a atuação da memória na vida dos antigos moradores de Porto Seguro no tocante à Ilha 
do Pacuio ou dos Aquários. Além disso, através dos relatos de cada ator social entrevistado pode-se descortinar como e quando aconteceram as transformações territoriais da ilha, detentora no passado de um território mais amplo que foi reduzido devido aos processos de dragagem em seu entorno. Cada fragmento de fala reconta parte da história que foi silenciada sobre a Ilha dos Aquários, talvez, para não interferir na semântico-semióticopragmática das atividades de turismo e lazer desenvolvidas atualmente no espaço em baila.

Constatou-se que, ao longo da história, que o Pacuio foi utilizado como caieira ${ }^{13}$, leprosário e ilha de fantasia sexual ${ }^{14}$, até se tornar empreendimento turístico e festivo, semântica que a caracteriza atualmente (outra semiótica que precisa ser estudada e analisada mais à frente).

Para que a Ilha dos Aquários adquirisse relevância no cenário turístico atual, foram necessárias transformações consideráveis na topografia/geografia/história do Pacuio para novos imaginários semiótico-semiológico-semânticos societários dos nativos e dos turistas que visitam o espaço. Nessa linha, cabe destacar que, ao longo da pesquisa, descobriu-se que as reconfigurações territoriais da Ilha ocorreram devido à ação de atores externos ao território com vistas à turistificação do topos em questão. Entretanto, tais mudanças não apagaram as vivências ocorridas no referido lócus, dado que a história encontra-se registrada na memória de cada individuo que viveu ou tomou conhecimento acerca do propósito da Ilha do Pacuio enquanto local destinado à reclusão social.

É importante relatar que os entrevistados forneceram informação que sustentam a ideia de que o processo de envio dos doentes não diagnosticados para o Pacuio era feito pela sociedade que exigia da família do "leproso" a sua retirada do convívio social, ato considerado normal para a época.

Por fim, este trabalho, além de trazer à tona parte da história silenciada sobre a Ilha, contribui para ampliar saberes acerca da arte do fenômeno de pesquisa no que concerne às narrativas acerca do leprosário do Pacuio a partir da análise do degredo como vigilância e punição sanitário-social.

\footnotetext{
Local de fazer cal.

$14 \quad$ No início desse processo eram trazidas garotas de outros lugares, algumas inclusive de marcas famosas para movimentar o lugar e incentivar o fluxo de pessoas. É preciso entender que os tempos eram outros e que as práticas que ocorriam ali eram ações de uma sociedade que via a mulher apenas como objeto sexual.
} 
Narrativas acerca do leprosário na Ilha do Pacuio em Porto Seguro: estruturas

de poder sobre o Mal de Hansen, degredo e abandono sócio-político-sanitário

\section{REFERÊNCIAS}

BAUMAN, Zygmunt; MAY, Tim. Aprendendo a pensar com a sociologia. Rio de Janeiro: Zahar, 2010.

BLOCH, Marc. Apologia da História ou o ofício de historiador. Zahar Editor, Rio de Janeiro, 2002.

CARA, Roberto Bustos. El turismo y los procesos de transformación territorial. In: RODRIGUES, A. B. (Org.). Turismo e geografia: reflexões teóricas e enfoques regionais. São Paulo: Huicitec, 1996.

CASTRO, E. A. São Roque: um exílio. Uma análise do papel do Hospital São Roque, Piraquara/PR na história da hanseníase no Paraná. Curitiba, 2003. 138 p. Monografia (Especialização em Análise Ambiental). Departamento de Geografia, Setor de Ciências da Terra da Universidade Federal do Paraná.

CORIOLANO, Luzia Neide Menezes Teixeira. o turismo nos discursos, nas políticas e no combate à pobreza. São Paulo, SP: Annablume, 2006.

CUNHA, V. S. O isolamento compulsório em questão: políticas de combate à Lepra no Brasil (1920-1941). Rio de Janeiro: Fundação Oswaldo Cruz, 2005. Dissertação de Mestrado em História das Ciências e da Saúde.

FOUCAULT, Michael. 0 Nascimento da Clínica. 4ª ed. Rio de Janeiro: Forense Universitária, 1994.

HALBWACHS, Maurice. A memória coletiva. São Paulo: Editora Revista dos Tribunais, 1990.

KOTLER, Philip. Administração de Marketing. 10 Edição, $7^{\mathrm{a}}$ reimpressão - Tradução Bazán Tecnologia e Linguística; revisão técnica Arão Sapiro. São Paulo: Prentice Hall, 2000.

LE GOFF, Jacques. Memória. In: História e memória. Trad. Bernardo Leitão et al. Campinas: Educamp, 1992. pp. 419-476.

NORA, P. Entre Memória e História. São Paulo: Revista do Programa de Estudos Pós-Graduados em História e do Departamento de História da PUC-SP, 1981.

POLLAK, Michael. Memória, esquecimento e silêncio. Estudos Históricos, Rio de Janeiro, v. 2, n. 3, p. 3-15, 1989.

RAFFESTIN. C. Por uma Geografia do Poder. Tradução Maria Cecília França. São Paulo: Ática, 1993. (Série: Geografia e Política. V. 29).

RAMOS, Leila Bitar Moukachar. Hanseníase e estigma no século XXI: narrativas de moradores de um território endêmico. 2017. 101 f. Tese (Doutorado em Ciências da Saúde) - Universidade Federal de Uberlândia, Uberlândia, 2017.

RICOEUR, Paul. Tempo e Narrativa. Tomo I. Trad. Constança Marcondes César. Campinas, SP: Papirus, 1994.

SANTANA, Elissandro dos Santos. Sugestão de pesquisa em torno das ações insustentáveis e déficits socioambientais no turismo de Porto Seguro-Bahia. Paripiranga: Revista Letrando, ISSN 2317-0735, 2016.

SANTOS, Milton. A natureza do espaço: técnica e tempo, razão e emoção. São Paulo, SP: Editora da Universidade de São Paulo (Edusp), 2002. 
JUSTA, A. A lepra no Ceará. Ceará Médico, ano 15, set./out. 1936. In SOUZA-ARAÚJO, H. C. História da lepra no Brasil. Rio de Janeiro: Departamento de Imprensa Nacional, 1956. In FEITOSA, Adília Maria Machado; ALMEIDA, Vera Lucia; FEITOSA, Aline Machado Monte. Hanseníase no Ceará: evolução histórica de um leprosário. Ceará: Revista Conhecer: debate entre o público e o privado, V. 1, N. 12, 2014.

ZAMPARONI, Valdemir. Lepra: doença, isolamento e segregação no contexto colonial em Moçambique. História, Ciências, Saúde - Manguinhos, Rio de Janeiro, v.24, n.1, jan.-mar. 2017. 